\title{
Brokeback Mountain e o segredo de todos nós: subjetividades na contemporaneidade
}

\author{
Brokeback Mountain and everyone's secret: subjectivities in \\ contemporary life
}

\author{
Maria Virgínia Filomena Cremasco ${ }^{1}$ \\ lara Pichioni Thielen ${ }^{2}$
}

\begin{abstract}
RESUMO
Este trabalho propõe uma discussão sobre a homossexualidade hoje, por intermédio de alguns elementos (sociais e psicanalíticos) já teorizados sobre o tema e outros de nossa atualidade, que afetam a visão e o posicionamento subjetivos sobre o assunto hoje (o zeigeist que caracterizaria a contemporaneidade com seus padrões culturais e intelectuais). Autores como Bauman (1998) e Jameson (1997) voltam-se para as transformações sociais como deflagradoras de mudanças subjetivas: fragmentação, superficialidade, heterogeneidade discursiva e espacialização do tempo e fim da unidade e da centralidade típicos da organização subjetiva da modernidade. A contemporaneidade é o cenário no qual esses novos elementos despontam e convocam posicionamentos subjetivos. É neste palco que a homossexualidade hoje deve ser vista e focalizada, tanto teórica quanto pragmaticamente. As possibilidades atuais de dissolução das identidades como construídas na coerência da modernidade (armaduras fixas e estereotipadas da personalidade) podem apontar uma ampliação no conceito de Saúde Mental e bem-estar.
\end{abstract}

Palavras-chaves: Homossexualidade. Identidade. Contemporaneidade. Subjetividades. Psicanálise.

\footnotetext{
1 Psicóloga, Doutora em Saúde Mental (Unicamp-2002), Professora do Departamento de Psicologia da Universidade Federal do Paraná, autora do livro: Psicopatologia e Disfunção Erétil: a clínica psicanalítica do impotente, São Paulo, Escuta, 2004, membro da Associação Universitária de Pesquisa em Psicopatologia Fundamental e Coordenadora do Núcleo de Estudos em Desenvolvimento Humano da UFPR.

Psicóloga, Doutora em Ciências Humanas (UFSC-2002), Professora do Departamento de Psicologia da Universidade Federal do Paraná, Coordenadora do Núcleo de Psicologia do Trânsito da UFPR.
} 


\begin{abstract}
This article consists of a discussion on homosexuality today based on a number of social and psychoanalytic aspects that have been theorized on elsewhere. Current aspects that affect perspectives and subjective positioning on the theme (the zeitgeist that characterizes contemporary life with its cultural and intellectual standards) are also referred to. Authors including Bauman (1998) and Jameson (1997) discuss social change as the generator of subjective changes such as fragmentation, superficiality, heterogeneous discourse and spatialization of time, as well as the end of unity and centrality that have been typical of the subjective organization of modernity. These new aspects come on stage before the backdrop of contemporary life, and call for subjective positions. It is in this perspective that homosexuality should be seen and focused on today, both theoretically and pragmatically. The current possibilities for the dissolution of identities constructed within the framework of modernity (identities seen as fixed and stereotyped armor of the personality) may indicate a broadened concept of mental health and well-being, and may free people for more creative and more enjoyable potentialities of fulfillment.
\end{abstract}

Key Words: Homosexuality. Identity. Contemporary life. Subjectivities. Psychoanalysis. 


\section{INTRODUÇÃO}

Em tempos de identidades virtuais e realidades plurais o cinema parece tomar fôlego para retratar a realidade que ainda costuma para muitos tirar o fôlego. O tema da homossexualidade e/ou do homoerotismo, fora das campanhas publicitárias de lingerie e outras de caráter mercadológico, foi e ainda é, muitas vezes, tratado à margem do publicamente visível: se dirigido à audiência aberta, comumente é focalizado de forma marginal e jocosa (vide caricaturas em novelas e jornais); se dirigido ao público específico (entenda-se o que se denominava GLS) é focalizado também marginalmente com mensagens de que 'só quem é, entende'.

O longa metragem Brokeback Mountain (Estados Unidos, 2005) conto da escritora ANNIE PROULX e de direção de ANG LEE, ganhador do Oscar de 2006 como melhor filme traz, finalmente, outra mensagem: sem caricaturas, de forma cuidadosamente sensível, o amor entre dois homens é abordado.

Críticas de cinema à parte, pois não fazem parte de nosso intuito aqui, o filme tem a coragem de retratar uma realidade muito próxima do real ainda de nossos dias (apesar de se passar na década de 60), sobre dois jovens que se desejam e se relacionam homoeroticamente.

Nenhuma novidade desde há 26 séculos, em que a didática e a estética homoerótica dos gregos confundiu nosso modo ocidental de pensar. O fato do filme não trazer nenhuma novidade ao tratar o assunto, a meu ver, é o que o faz digno da indicação ao Oscar: não há novidade na homossexualidade, mas é inovador ao tratá-la de forma acessível e aberta a todos: o amor e o desejo publicamente visíveis, independentemente dos gêneros que os repartem. A homossexualidade na sala de estar sem ter que pedir autorização ou desculpas por se fazer notar.

Talvez fosse mesmo difícil imaginar outro fim ao filme senão a separação dos cowboys que se amaram nos anos 60, e a mensagem ao final de que o amor pode abrir horizontes emocionais, mudar o que parecia já por demais cristalizado no modo de ser de um deles, também não é novidade; mas traz algo que vai além do estético ao se tratar do amor entre dois homens: retrata a ética que atribuímos a esse sentimento amoroso, despregada do preconceito que impede que sejamos 
afetados e melhorados por ele. Ética que reconduz nosso olhar e respeito pelo humano e seus sentimentos.

Este artigo propõe um espaço de discussão sobre a homossexualidade, por intermédio de alguns elementos (sociais e psicanalíticos) já teorizados sobre o tema e outros de nossa atualidade que afetam a visão e o posicionamento subjetivos sobre o assunto hoje (o zeigeist que caracterizaria a contemporaneidade com seus padrões culturais e intelectuais).

Brokeback Mountain assim como Longe do Paraíso (Estados Unidos, 2002) dirigido por Todd Haynes - sobre a vida perfeita de uma dona de casa que fica em ruínas após descobrir o homossexualismo de seu marido e se aproximar de um homem negro, o que causa o preconceito dos vizinhos - , respectivamente, retratam para o século XXI a homossexualidade nas décadas de 60 e 50, trazendo para a atualidade possibilidades de se repensar o tema.

Falar de homossexualidade hoje é, sem dúvida, ser convidado a debruçar-se de forma inovadora sobre algo já tão falado e estudado quanto mal compreendido. Dedicarmo-nos a esta reflexão, por si só, já não nos colocaria numa parcialidade quanto ao modo de olharmos para a sexualidade? Por que não falarmos também da heterossexualidade ou das 'sexualidades' possíveis?

Graña (1998a) no prefácio de seu livro Homossexualidade: formulações psicanalíticas, justifica-se por dedicar toda uma publicação ao reexame da questão em psicanálise naquele fim de século/milênio:

É o compromisso iluminista stricto sensu que definitivamente assumimos, ao tornar-nos psicanalistas, com as premissas éticas humanistas que implicam num ineludível enfrentamento das pretensões hegemônicas obscurantistas (GRAÑA, 1998a, p.14).

Portanto, trata-se de 'ainda' podermos lançar luz ou mais precisamente, não obscurecer o que já não dá mais para esconder. Como bem os filmes Brokeback Mountain e Longe do Paraíso retratam: anos de ignorância, hipocrisia e violência se arrastaram e se arrastam em torno da homossexualidade e dos homossexuais, assim como também é inegável que novos elementos teóricos e culturais despontam a cada dia, tornando mais complexos os posicionamentos ou inquietando antigas crenças. 
Do que afinal se trata? Em pleno século XXI, ainda somos convocados a explicá-la? Temos eticamente ainda que tratar a homossexualidade como 'desvio'? Se a normatização vai por outra via - a heterossexualidade - também naturalizamos que esse 'desvio' tenha que ser explicado?

\section{DEUS CRIOU O HOMEM QUE CRIOU A MULHER QUE CRIARAM OS SEXOS}

A naturalização da heterossexualidade, fruto dos modelos científicos de homem e mulher do século XIX, tornou muito limitada nossa visão das potencialidades humanas. Para Costa (1996) o sexo da medicina política oitocentista bissexualizou os ossos, os nervos e o prazer sensual:

A partir da distinção radical dos homens e mulheres, quanto à anatomia e à fisiologia reprodutivas, ocorreu a bissexualização do prazer sensual e a definitiva sexualização da distinção dos gêneros masculino e feminino. Os gêneros, que antes eram diferenciados pela medida metafísica da forma ideal do corpo, tornaram-se epifenômenos da diferença original dos dois sexos (COSTA, 1996, p.84).

Antes da construção da diferença entre os sexos (two-sex model), seria teoricamente impensável a divisão dos sujeitos em homo e heterossexuais. O sexo da mulher passou a ter uma especificidade que era necessária à reprodução da vida humana, não mais vista como no antigo modelo (one-sex model), que perdurou até o século XVIII, no qual era tratada biologicamente como um homem invertido e inferior.

A partir daí a mulher será vista como possuindo um outro sexo, com as especificidades do seu aparelho reprodutor. A imagem da inversão será então colada ao homem, o invertido será o homossexual e sua inversão, como antinatural, será vista como uma perversão.

Sua inversão será perversão porque seu corpo de homem será portador da sexualidade feminina que acabara de ser criada. $O$ invertido apresentava um duplo desvio: sua sensibilidade nervosa e seu prazer sensual eram femininos. Seu sexo foi, por isso mesmo, definido como contrário aos interesses da reprodução biológica. Igual aos vaporosos e histéricos, possuía a sensibilidade nervosa da mulher. Mas, além disso, era incapaz de reproduzir. Por esta razão, os histéricos e vaporosos serão abandonados à própria miséria, enquanto o homossexual será posto na lupa da ciência junto com outros perversos (COSTA. 1996, p.85). 
É necessário entendermos como a construção científica da diferença anatômica dos sexos acabou por instituir a homossexualidade como perversão desvio do que passou a ser considerado como "natural".

Para Foucault (1990) a categoria psicológica, psiquiátrica e médica da homossexualidade constituiu-se no dia em que foi caracterizada uma certa qualidade da sensibilidade sexual que invertia, no sujeito, o masculino e o feminino uma espécie de androginia interior, um hermafroditismo da alma, como se fosse uma outra espécie. A ciência moderna, baseada em observações naturalistas, passa a determinar, pelo discurso, a 'naturalidade' das coisas humanas e é nesse panorama que a homossexualidade passa a ser vista como anti-natural, anômala e perversa.

\section{PERVERSOS, HOMOSSEXUAIS E POSSÍVEIS}

O conceito de perversão aparece em Freud (1905/1996) pela primeira vez nos "Três Ensaios sobre a Teoria da Sexualidade": a fixação na vida adulta de características típicas da sexualidade infantil que é pré-genital (denominadas perverso-polimorfas), em detrimento da sexualidade adulta genital, considerada normal. Laplanche e Pontalis (1973) assim abordam o conceito de perversão no pensamento de Freud: "desvio do ato sexual 'normal' quando este é definido como sendo o coito com uma pessoa do sexo oposto, dirigido à consecução do orgasmo mediante a penetração genital" (LAPLANCHE; PONTALIS, 1973, p.306).

No capítulo "As Aberrações Sexuais" dos "Três Ensaios", Freud (1905/1996) denomina como 'invertidos' e não perversos, os homossexuais. Freud sempre articulou o saber psicanalítico com o contexto social de seu tempo e embora não faça uma correlação direta homossexualidade = perversão, sem dúvida o enfoque de desviante patologiza essa qualidade da sexualidade. 
Para a psicanálise, dentro das vicissitudes do desenvolvimento infantil, até podemos enumerar certos aspectos da relação primitiva com os pais (situação edípica) que parecem estar presentes na história de vida de homossexuais (um pai visto como 'fraco' e uma mãe que não favorece a independência do filho, dificuldade em aceitar a castração e a diferença dos sexos, por exemplo). Contudo, como a clínica nos revela, esses fatores estão presentes também nos sofrimentos dos heterossexuais e afirmar que são os 'causadores' ou 'deflagradores' de certa preferência sexual é, no mínimo, reduzir na causalidade não funcional a compreensão psicodinâmica do sujeito - e isso não é psicanálise.

Desde Freud, os psicanalistas, ao longo dos anos, têm se posicionado e falado de formas diversas sobre o tema. Houve um crescente descentramento da associação homossexualidade-perversão no sentido de descolamento lingüístico da conotação depreciativa: para os que se referem aos homossexuais como 'perversos', psicanaliticamente falando, fazem-no como possível efeito semiótico dos elementos estruturais da personalidade, ou seja, paradigmático da psicodinâmica envolvida. Isso absolutamente, a nosso ver, não elimina o risco de obscurantismo (e seus efeitos nocivos) ao remeter a homossexualidade ao mesmo campo semântico da perversão, com todas suas implicações moralistas, inclusive patológicas.

McDougall (1997) adota um ponto de vista mais construtivo, como ela mesma se refere, acerca da significação e do propósito das estruturas psíquicas, dos sintomas psicológicos e das sexualidades sintomáticas. Neste sentido, a autora diz que no âmbito da vida de fantasia erótica, todo mundo é livre de constrangimento externo; os únicos fatores inibidores são os impostos pelas figuras parentais internas. O que então poderia se denominar de fantasia erótica 'normal' ou 'perversa'? Ela então reservaria o uso da palavra perversão para a “(...) tentativa de impor a imaginação erótica a um outro que não consentisse nisso ou que não fosse responsável." (MCDOUGALL, 1997, p.192).

O indivíduo perverso seria aquele totalmente indiferente às necessidades e desejos do outro. A escolha objetal de um sujeito, em si, não revelaria em nada sua psicodinâmica, dificuldades ou patologias psicológicas.

Nessa visão, dentro das possibilidades de escolhas sexuais, ser homossexual aponta apenas para uma delas e isso, definitivamente, não caracteriza 
que um homossexual tenha essa ou aquela patologia ou enfermidade psíquica (CREMASCO GRASSI, 2002). Para Stubrin (1998, p.65-66):

Isso não significa que não encontremos pessoas homossexuais com sérios conflitos psíquicos, mas que não são dependentes da homossexualidade, e sim da patologia básica do sujeito ao qual estamos escutando.

Desde Freud (1916-1917/1996), para a psicanálise, existem apontamentos sobre como os considerados traços ou elementos 'perversos', participam da riqueza dos nossos scripts sexuais sem que isso nos represente sofrimento ou dor:

Existe algo mais que devo acrescentar a fim de completar nosso ponto de
vista referente às perversões sexuais. Por mais infames que possam ser,
por mais nítido que se faça o contraste com a atividade sexual normal, uma
reflexão tranqüila mostrará que um ou outro traço de perversão raramente
está ausente da vida sexual das pessoas normais. Pode-se alegar que até
mesmo um beijo seria considerado ato pervertido, de vez que consiste na
junção de duas zonas erógenas orais em vez de dois genitais
(FREUD,
(F16-1917/1996, p.326-327).

Assim a psicanálise desvelava aspectos culturais e sociais considerados desviantes como inerentes à própria sexualidade. O segredo de todos nós.

Em 1973, a Associação Americana de Psiquiatria retirou a homossexualidade do seu Manual Diagnóstico e Estatístico de Transtornos Mentais (DSM), deixando de considerá-la como uma patologia, de forma mais realista focalizando o tratamento no sofrimento das pessoas, como a egodistonia, e não em convenções moralistas e normativas que a transformavam em uma doença por si só. Em 1985 o Conselho Federal de Medicina do Brasil (CFM) retira também a homossexualidade da condição de desvio sexual. Hoje são os pais de filhos gays que devem mudar seu jeito de encarar a homossexualidade e não os filhos que devem ser tratados ou curados para se adequar à suposta norma.

Assim como Graña (1998b) pronunciou no XL Congresso Psicanalítico Internacional: "analisamos as pessoas que sofrem, ou que começaram a sofrer, e não desvios sexuais". Aproximarmo-nos da sexualidade humana, como diz McDougall (1997), trata-se de focalizarmos o campo sexual e como

a maioria das pessoas vivencia seus atos eróticos e escolhas objetais como egossintônicos, sejam ou não julgados 'perversos' pelos outros. As variedades específicas da preferência sexual só se tornam problema analisável na medida em que os indivíduos envolvidos considerem sua forma normal de sexualidade como fonte de sofrimento e, portanto, a vivenciem como egodistônica (McDOUGALL, 1997, p.187). 
Ampliarmos nossa compreensão da homossexualidade como uma das possibilidades de expressão da sexualidade humana, sem rotulá-la em convenções ou normas, é expandirmos também as focalizações sobre o humano e suas possibilidades. A genética tem realizado grandes avanços nesse sentido ao revelar a amplitude do universo interno humano e suas possibilidades, antes impensáveis, em seus estudos com genoma.

Fora da miopia das convenções normativas, o posicionamento teórico dos estudiosos das questões de gênero e identidade, psicanalistas ou não, afirmam que, se devemos explicar a homossexualidade, devemos também, na mesma condição, explicar a heterossexualidade. Money (1988) diz que tanto a hetero quanto a homossexualidade não são preferências ou opções. É algo que acontece, ao acaso, como ser destro, canhoto, alto ou baixo.

Caricaturar o homossexual parece ser uma forma segura de mantê-lo diferente, marginal, componente de um grupo à parte dos considerados 'normais': como se o homossexual fosse um desejável terceiro gênero.

4. TRAÇOS DA CONTEMPORANEIDADE, GURUS GAYS DO BEM ESTAR ATUAL: A VIRTUALIDADE NA SALA DE ESTAR

Atualmente é crescente a idealização em torno dessa diferença, essa 'terceiridade' de gênero, como se por características específicas (como se descobriu em meados do século XIX na mulher) que lhes permitem participar dos outros dois gêneros (por possuírem o corpo de um e supostamente o desejo de outro), eles tivessem então uma visão mais clara e adequada sobre o existir e, principalmente, sobre como se relacionar com os mortais.

Séries televisivas, como Queer Eye For The Straight Guy (Scout Productions), por exemplo, que se auto-intitulam como um guia de uma hora para construir um heterossexual melhor, protagonizado por cinco conselheiros gays, e livros dirigidos a heterossexuais de autoria homossexual, são cada vez mais comuns, proporcional ao sucesso de vendas que realizam. Os produtos voltados ao mercado gay também aumentam na mesma proporção em que são vendidos. 
Uma pesquisa da agência de publicidade Prime Access e da firma Ribendell Media apontou que a despesa em publicidade nos meios de comunicação dirigidos à comunidade gay foi de 207 milhões de dólares em 2004, uma alta de $28,4 \%$ em relação a 2003.

Howard Buford (1997), presidente da Prime Access, agência orientada exclusivamente às comunidades gay, negra e hispânica, diz que o intenso debate sobre os casamentos entre homossexuais nos Estados Unidos, em vez de desestimular, incentivou os anunciantes a investirem mais no mercado gay. Segundo Buford, este mercado está passando da periferia para o centro e o uso do imaginário homossexual na publicidade poderia seguir a mesma trajetória da representação negra. Uma das tendências apontadas por ele é que, nos próximos cinco a dez anos, a publicidade poderia deixar de apresentar gays caricaturizados, já que as imagens dos homossexuais são cada vez mais aceitas. No mercado consumista, Buford acredita que os anunciantes se tornarão mais sofisticados, deixarão de lado os estereótipos e começarão a retratar os homossexuais como especialistas em outros assuntos além da moda, da decoração e do cuidado pessoal - áreas que parecem refletir a cultura narcísica normalmente atribuída a eles.

No momento, os 'homo' agora são agora vistos como gurus aconselhando os 'hetero' sobre as mais variadas questões humanas, mas sobretudo, como bem viver. Cria-se uma 'aura' de sabedoria atribuída ao misticismo e à crença de que os homossexuais são felizes ou pelo menos sabem como ser ao transporem o abismo das diferenças sexuais.

Talvez estejamos diante do conhecido fenômeno do pêndulo no qual para atingir o equilíbrio depois de estar em um extremo, deve ir até o outro extremo para então, basculando entre os lados, encontrar seu lugar ao meio. Essa mudança no modo de se focalizar a homossexualidade, do sempre pejorativo e patológico como retratado nos filmes das décadas de 50 e 60 para uma certa sofisticação cult ou mesmo lúdica, ainda a situa de forma estereotipada, entretanto parece possibilitar uma certa visibilidade mais palatável ou flexível aos olhares atuais ainda conservadores.

Esse hermafroditismo psíquico atribuído ao suposto 'terceiro' gênero parece refletir as características de pluralidade que comumente se associa à 
contemporaneidade. Uma delas é a dissolução das identidades em prol de formas de estar plurais, vários selves que coabitariam numa mesma pessoa, como veremos a seguir.

O Oscar de 2006 para Brokeback Mountain parece refletir, como anunciado na Revista Veja de 25/02/06, uma mudança na mentalidade americana com relação à aceitação de temas outrora considerados proibidos. A catástrofe de 11 de setembro de 2001 é referenciada como uma das responsáveis por esta 'abertura' no imaginário sócio-cultural. Como se a imprevisibilidade com que foram atingidos revelasse aos americanos a necessidade de estarem mais conectados com os assuntos do mundo e as mudanças que vêm ocorrendo, bem como a fragilidade de suas convicções.

Autores como Bauman (1998) e Jameson (1997) voltam-se para as transformações sociais como deflagradoras de mudanças subjetivas, como as descritas com os americanos. Em um artigo sobre as conseqüências subjetivas das transformações que o mundo vem sofrendo nas últimas décadas, Romão-Dias e Nicolaci-da-Costa (2005) dizem que as mudanças na subjetividade contemporânea têm sido estudadas por vários autores (BAUMAN (1998), JAMESON (1997), SENNET (1999), TURKLE (1997), dentre outros).

Em seu artigo são apresentados os modelos de Jameson (1995, 1997) e Turkle (1997) sobre a organização subjetiva atual e tomados como referência para discutir os resultados de uma pesquisa com usuários brasileiros da Internet. Para as autoras, a subjetividade contemporânea parece ser caracterizada por selves múltiplos como proposto por Turkle (1997) mas criticam o uso de modelos patológicos, como da esquizofrenia, utilizados por essa autora e por Jameson (1997) para retratarem a atualidade.

Tomaremos alguns elementos apontados por esses autores como referências do que estamos denominando de contemporaneidade e para ampliarmos a compreensão de como as mudanças conceituais podem encontrar espaço de aceitação social: fragmentação, superficialidade, heterogeneidade de discursos e espacialização do tempo para Jameson (1997) e fim da unidade e da centralidade típicos da organização subjetiva da modernidade para Turkle (1997) que acredita 
que os objetos do pós-modernismo agora existem fora da ficção científica nas informações e conexões da Internet.

O modelo da virtualidade e da Internet parece atender ao que aqui denominamos de novos elementos da contemporaneidade: outras relações com o tempo e a temporalidade nas quais tudo se passa como num eterno presente abolindo-se o tempo de espera entre dois eventos (CREMASCO GRASSI, 2007); a possibilidade de um sujeito multiplicar-se em várias identidades virtuais numa descentralização egóica impensável na modernidade (vários selves de Turkle, 1997); acesso as mais variadas e atuais informações, globalização, ressignificação dos contatos corporais e interpessoais (pelos chats e canais de conversa on line); novos contratos intersubjetivos para os antigos modelos de casal (cite-se traição e fidelidade virtuais, grupos virtuais de troca de fantasias, comunidades, etc.); e família (temporalidade e educação dos filhos ressignificada), etc.

A contemporaneidade é o cenário no qual esses novos elementos despontam e convocam posicionamentos subjetivos. É neste palco que a sexualidade e suas qualidades, como por exemplo a homossexualidade, hoje devem ser vistas e focalizadas, tanto teórica quanto pragmaticamente. As possibilidades atuais de dissolução das identidades como construídas na coerência da modernidade (armaduras fixas e estereotipadas da personalidade) podem apontar uma ampliação no conceito de Saúde Mental e bem-estar e libertar as pessoas para potencialidades mais criativas e prazerosas de auto-realização. 


\section{REFERÊNCIAS}

BAUMAN, Z. O mal estar na pós-modernidade. Rio de Janeiro: Jorge Zahar, 1998

BUFORD, $\mathrm{H}$. The gay market goes mainstream. Disponível em:

http://www.primeacess.net/gaymarket_mainstream.pdf. Acesso em 04 jun. 2007

COSTA, J. F. O referente da identidade homossexual. In: PARKER, R; BARBOSA, R. M. (Orgs.). Sexualidades Brasileiras. Rio de Janeiro: Relume Dumará, ABIA:IMS/UERJ, 1996. p. 63-89.

COSTA, J. F. A inocência e o vício: estudos sobre o homoerotismo. Rio de Janeiro: Relume/Dumará,1992.

CREMASCO GRASSI, M. V. F. Temporalidade e Contemporaneidade. Pulsional Revista de Psicanálise, São Paulo, v. 1, n. 1, p. 46-55, out. 2007.

CREMASCO GRASSI, M. V. F. Roberto: uma fantasia (homo)sexual In: CREMASCO GRASSI, M. V. F. Psicopatologia e Disfunção erétil: a clínica psicanalítica do impotente. São Paulo: Escuta, 2002. p. 206-214.

FOUCAULT, M. História da Sexualidade I: a vontade de saber. Rio de Janeiro: Graal, 1990.

FREUD, S. Três Ensaios sobre a Teoria da Sexualidade (1905). In: FREUD, S. Edição Standard Brasileira das Obras Psicológicas Completas de Sigmund Freud. Trad. Jayme Salomão. Rio de Janeiro: Imago, 1996. v. 7, p. 118-228.

FREUD, S. Conferência XXI: O Desenvolvimento da Libido e as Organizações Sexuais (1916-1917). In: FREUD, S. Edição Standard Brasileira das Obras Psicológicas Completas de Sigmund Freud. Trad. Jayme Salomão. Rio de Janeiro: Imago, 1996. v. 16, p. 375-395.

GRAÑA, R. B. Homossexualidade: formulações psicanalíticas atuais. Porto Alegre: Artes Médicas, 1998a. 
GRAÑA, R. B. Além do desvio sexual: analisando a assim chamada perversão. Revista Brasileira de Psicanálise, v.32, n.1, p.83-101, $1998 \mathrm{~b}$.

JAMESON, F. Espaço e Imagem: Teorias do Pós-Moderno e outros Ensaios. Rio de Janeiro: UFRJ, 1995.

JAMESON, F. Pós-modernismo: a lógica cultural do capitalismo tardio. São Paulo: Ática, 1997.

LAPLANCHE, J.; PONTALIS, J. B. The language of psychoanalysis. New York: Norton, 1973.

MCDOUGALL, J. As múltiplas faces de Eros: uma exploração psicoanalítica da sexualidade humana. São Paulo: Martins Fontes, 1997.

MONEY, J. The sexology of erotic orientation. New York: Oxford University Press, 1988.

ROMÃO-DIAS, D; NICOLACI-DA-COSTA, A. M. Eu Posso me Ver como Sendo Dois, Três ou Mais: algumas reflexões sobre a subjetividade contemporânea.

Psicologia: Ciência e Profissão. Conselho Federal de Psicologia. Brasília, v.1, n. 1, p. $70-87,1981$.

SENNET, R. A corrosão do caráter: conseqüências pessoais do trabalho no novo capitalismo. Rio de Janeiro: Record, 1999.

STUBRIN, J. P. A psicanálise e as homossexualidades. In: GRAÑA, R. B. Homossexualidade: formulações psicanalíticas atuais. Porto Alegre: Artes Médicas, 1998. p. 65-84.

TURKLE, S. Life on screen: identity in the age of internet. New York: Touchstone, 1997. Disponível em: http://mixbrasil.uol.com.br/anuncie/pub.asp. Acesso em 03 mar. 2006. 